ORIGINAL RESEARCH PAPER

\title{
OPTIMIZATION OF PHENOLIC COMPOUND RECOVERY AND ANTIOXIDANT ACTIVITY FROM FUMARIA OFFICINALIS L. USING RESPONSE SURFACE METHODOLOGY
}

\author{
SABIHA KHAMTACHE-ABDERRAHIM ${ }^{1}$, SONIA YAHIAOUI ${ }^{2}$, AMAR OTMANI $^{2}$, \\ MOSTAPHA BACHIR-BEY ${ }^{* 2}$
${ }^{I}$ Laboratoire de Biotechnologies des plantes et Ethnobotanique, Faculté des Sciences de la Nature et de la Vie, Université de Bejaia, 06000 Bejaia, Algérie de Bejaia, 06000 Bejaia, Algeria \\ ${ }^{2}$ Laboratoire de Biochimie Appliquée, Faculté des Sciences de la Nature et de la Vie, Université \\ *corresponding author: bachirbeymustapha@gmail.com, mostaphabachirbey@univ-bejaia.dz
}

Received on 3 June 2021

Revised on 24 November 2021

\begin{abstract}
The purpose of this study was to optimize the extraction of antioxidant phenolic compounds from Fumaria officinalis by two approaches, single-factor experiment and response surface methodology (RSM). After extraction optimization, the content of polyphenols, flavonoids, and tannins was performed. Antioxidant activities of optimal extract were evaluated by DPPH, ABTS, and iron chelating activities. Single-factor experiments showed that all extraction parameters had significant effects $(\mathrm{p}<0.05)$ on total phenolic content and free radical scavenging activity. From the optimization process using response surface methodology through Box-Behnken design regarding the three selected significant parameters (solvent concentration, extraction time, and temperature), it was established that the best extraction conditions were $47 \%$ methanol, $54.40^{\circ} \mathrm{C}$, and $168.02 \mathrm{~min}$, respectively. Under these optimal conditions, the recorded values for TPC and DPPH scavenging activity were successively $1510.10 \mathrm{mg}$ GAE/100g DW and 69.85\%. These results were in accordance with model predictions indicating that the model was suitable for the extraction process. Furthermore, higher flavonoids and tannins contents and strong iron-chelating and ABTS scavenging activities were obtained.
\end{abstract}

Keywords: Fumaria officinalis, optimization, single-factor experiments, response surface methodology, phenolic compounds, antioxidant activity

\section{Introduction}

There has been growing interest in researching and developing natural of natural antioxidants plant-based extracts to obtain bioactive compounds for pharmaceutical

https://doi.org/10.35219/foodtechnology.2021.2.08 
and food industries (Hrelia and Angeloni, 2020). These compounds have demonstrated antioxidant characteristics that help disease risk reduction and prevent several human pathologies such as cancer, inflammation, and chronic diseases (Teodoro, 2019). In this respect, Fumaria officinalis L., which belongs to the family of Fumariaceae and has a wide distribution in Europe and Northern Africa (Suau et al., 2005), is one of the oldest medicinal plants rich in phenolic compounds and alkaloids (Khamtache-Abderrahim et al., 2016). Moreover, many therapeutic activities attributed to $F$. officinalis were validated by intensive recent research and clinical studies, such as antibacterial, analgesic, antioxidant, and beneficial effects in irritable bowel syndrome and biliary disorders (Al-Snafi, 2020), a strong anticancer activity (Adham et al., 2021), aphrodisiac, antidiabetic, and anti-inflammatory effects (Raafat and El-Zahaby, 2020). These activities are due to the diverse bioactive molecules such as phenolic acids, tannins, coumarins, terpenoids, and alkaloids.

Phenolic compounds have gained high interest and attracted more and more researchers and industrials due to their biological activity. The extraction is the first step for the recovery of these bioactive compounds that must be performed adequately. The extraction process can be achieved following the sequential method or with experimental design. The first approach allows studying only one factor at a time and omits the interaction between parameters, however, it permits fixing the lower and upper levels of each factor in order to limit the study range for the experimental design. This last approach has been demonstrated to be a helpful tool that can overcome the difficulties encountered in one-factor experiments, minimizing the number of trials, allowing the relationship between responses and factors to be determined, and also permits the checking of possible interaction between variables (Bezerra et al., 2008; Jorge et al., 2013).

The extraction of phenolic compounds from $F$. officinalis has been performed by different solvents (water alone, methanol, and ethanol or their mixture with water) using different methods such as maceration, sonication, Soxhlet, and water bath during various extraction times (from 15 min to 10 days) with using different temperatures $\left(20-95^{\circ} \mathrm{C}\right)$ (Păltinean et al., 2017; Edziri et al., 2020). In order to propose the best procedure for phenolic recovery from fumitory, it is recommended to optimize the extraction process. As far as we know, no study concerned the optimization of extraction of phenolic compounds from $F$. officinalis by response surface methodology (RSM); therefore, the main objective of this study was to optimize phenolic compounds extraction using the sequential procedure followed by RSM. Afterward, the optimal extract was evaluated for its total polyphenols, flavonoid, and tannin contents, and antioxidant activity by DPPH, ABTS, and iron-chelating assays.

\section{Materials and methods}

\section{Plant material}

The harvest of the aerial part of Fumaria officinalis was carried out from the region of Akbou (Bejaia, Algeria) during April 2019. Samples were dried in a free area 
and grounded with a crusher (IKA A11, Staufen, Germany). The powder obtained was sieved using an electric sieve and the powder with a diameter from 250 to 45 $\mu \mathrm{m}$ was recovered and stored at $4^{\circ} \mathrm{C}$ until further analysis.

\section{Chemicals}

Folin-Ciocalteu reagent was obtained from Biochem, Chemopharma (Montreal, Quebec); sodium carbonate was purchased from Biochem, Chemopharma (Cosne Sur Loire, France), gallic acid, acetone (99.78\% purity), methanol (99.7\% purity), and ethanol (99.5\% purity) were from Prolabo (VWR International S.A.S, Fontenay-sous-Bois, France). All other chemicals were purchased from Sigma Chemical (Sigma-Aldrich, Sternheim, Germany).

\section{Extraction of phenolic compounds}

Sample powder was weighed $(0.2 \mathrm{~g})$ and homogenized in $10 \mathrm{~mL}$ of extraction solvent (water, $50 \%$ methanol, $50 \%$ ethanol, and $50 \%$ acetone) the mixture was stirred in a water bath shaker equipped with a stirrer (WB 22, Memmert, Schwabach, Germany). After centrifugation at $5000 \mathrm{rpm}$ for $10 \mathrm{~min}$, the mixture was filtered through Whatman 4 filter paper.

\section{Single-factor experiment}

Five extraction parameters were considered to optimize the extraction of phenolic compounds and the free radical scavenging activity of $F$. officinalis by a single factor experiment. The optimized parameters were solvent type (50\% acetone, 50\% ethanol, $50 \%$ methanol, and water), solvent concentration $(25-00 \%$, v/v), sample to solvent ratio $(0.2 / 10-0.8 / 10 \mathrm{~g} / \mathrm{mL})$, extraction temperature $\left(25-70^{\circ} \mathrm{C}\right)$, and extraction time (30 - $120 \mathrm{~min})$.

\section{Response surface methodology experiment}

The variables studied by response surface methodology were methanol concentration $\left(x_{1}, \%, \mathrm{v} / \mathrm{v}\right)$, extraction temperature $\left(x_{2},{ }^{\circ} \mathrm{C}\right)$, and extraction time $\left(x_{3}\right.$, $\min )$. The three considered levels of the studied variables, the lower $(-1)$, the central (0), and the upper $(+1)$, were set for methanol concentration at 20,50, and $80 \%$, extraction temperature at 35,55 , and $75^{\circ} \mathrm{C}$, and extraction time at 50,120 , and 190min. The Box-Behnken design with three central points was adopted for studying two responses, total phenolic content (TPC) and DPPH free radical scavenging activity (FRSA). The responses were given as a second-degree polynomial model according to equation 1 .

$$
y=a_{0}+\sum_{i=1}^{3} a_{i} x_{i}+\sum_{i=1}^{3} a_{i i} x_{i}^{2}+\sum_{i=1}^{3} \sum_{j=1}^{3} a_{i j} x_{i} x_{j}(i \neq j)
$$

Where $a_{0}, a_{i}, a_{i i}$, and $a_{i j}$ are the regression coefficients for intercept, linear, quadratic, and interaction terms, respectively, while $x_{i}$ and $x_{j}$ are the independent variables.

\section{Verification of the model}

The optimum conditions for phenolic extraction and antioxidant activity of $F$. officinalis were obtained using the predictive equations of RSM. In addition, 
experimental and predicted phenolic compounds and free radical scavenging activity (DPPH) were compared to check model validity.

\section{Determination of antioxidant parameters}

\section{Total phenolic content}

TPC was estimated according to the method of Naithani et al. (2006). A volume of $100 \mu \mathrm{L}$ of the extract was mixed with the same volume of the Folin-Ciocalteu reagent $(50 \%)$ and $2 \mathrm{~mL}$ of sodium carbonate $(2 \%$, w/v). After 30 minutes of incubation in darkness, the absorbance was measured at $750 \mathrm{~nm}$. Gallic acid was used as a standard and the results were expressed as milligrams of gallic acid equivalent per 100 grams of dry weight (mg AGE/100g DW).

\section{Total flavonoid content}

The total flavonoid content (TFC) was measured according to the protocol described by Quettier-Deleu et al. (2000). In brief, a volume of $1.5 \mathrm{~mL}$ of extract was mixed with an equal volume of aluminum chloride solution $(2 \%, w / v)$. After incubating for $15 \mathrm{~min}$, the absorbance was measured at $430 \mathrm{~nm}$, and the results were expressed as $\mathrm{mg}$ of quercetin equivalent per 100 grams of dry weight (mg QE/100g DW).

\section{Total tannin content (TTC)}

The method for estimating the content of condensed tannins is proposed by Hillis and Swain (1959). The vanillin reagent was prepared by dissolving $1 \mathrm{~g}$ of the vanillin in $100 \mathrm{~mL}$ of sulfuric acid $(70 \%)$ then $2 \mathrm{~mL}$ of this reagent was mixed with $1 \mathrm{~mL}$ of extract. After incubation at $50^{\circ} \mathrm{C}$ for $20 \mathrm{~min}$, the absorbance was measured at $500 \mathrm{~nm}$. The results were expressed in gram catechin equivalent per 100 grams of dry weight (mg CE/100g DW).

Free radical scavenging activity (FRSA)

DPPH assay was performed according to Brand-Williams et al. (1995). A volume of $100 \mu \mathrm{L}$ of the extract was mixed with $1000 \mu \mathrm{L}$ of DPPH solution $(60 \mathrm{mM}$ in methanol). After $30 \mathrm{~min}$ of incubation, the absorbance was measured at $515 \mathrm{~nm}$. The results were expressed as a percentage according to equation 2 .

$$
\mathrm{DPPH}(\%)=\frac{\mathrm{Ac}-\mathrm{As}}{\mathrm{Ac}} \times 100
$$

where Ac: Absorbance of the control, Ae: Absorbance of the extract.

\section{ABTS radical scavenging assay}

The scavenging of the cationic radical $\mathrm{ABTS}^{\cdot+}$ was determined according to $\mathrm{Re}$ et al. (1999). Briefly, $0.1 \mathrm{~mL}$ of ethanolic solution of ABTS was mixed with $20 \mu \mathrm{L}$ of extract and the absorbance was read at $734 \mathrm{~nm}$ after seven minutes of incubation. The percentage of radical inhibition was calculated using equation 3 .

$$
\operatorname{ABTS}(\%)=\frac{(\mathrm{Ac}-\mathrm{As})}{\mathrm{Ac}} \times 100
$$

where Ac: Absorbance of the control, Ae: Absorbance of the extract.

\section{Ferrous ion chelating activity}


The $\mathrm{Fe}^{2+}$ chelation of extract was measured according to the procedure described by Wang et al. (2008). A volume of extract $(500 \mu \mathrm{L})$ was mixed with $50 \mu \mathrm{L}$ of iron (II) chloride $(2 \mathrm{mM})$ and $1.6 \mathrm{~mL}$ of distilled water. After $5 \mathrm{~min}$ of incubation, 100 $\mu \mathrm{L}$ of ferrozine $(5 \mathrm{mM})$ were mixed and left for an additional $5 \mathrm{~min}$. The absorbance was then measured at $562 \mathrm{~nm}$ against a blank. The chelating activity of the sample was calculated by equation 4 .

$$
\text { Chelating activity }(\%)=\frac{1-(A 1-A 2)}{A 0} \times 100
$$

where $\mathrm{A}_{0}$ : Absorbance of the control (without extract), $\mathrm{A}_{1}$ : Absorbance of the extract, $\mathrm{A}_{2}$ : absorbance without ferrozine.

\section{Statistical analysis}

All analyses were carried out in triplicate and the results were expressed as mean \pm standard deviation. Statistical analyses were performed using Statistica software (version 5.5.fr, Stat Soft, Inc, Tulsa, USA). One-way analysis of variance (ANOVA) with the LSD (least significant difference) test was used to find out the significant differences $(p<0.05)$ between means. The JMP10 software (statistical analysis system Inc., SAS) was used to analyze the results of the response surface methodology experiment.

\section{Results and discussion}

\section{Single-factor experiments}

\section{Effect of solvent type on total phenolic content and free radical scavenging}

The effect of solvent type on TPC and FRSA from $F$. officinalis extract was represented in Figures 1a and 2a, respectively. It can be seen that solvent type significantly affected polyphenols recovery and DPPH scavenging activity. The four solvents can be ranked according to their extraction efficiency in the following order: 50:50 methanol-water mixture > 50:50 ethanol-water mixture > 50:50 acetone-water mixture > water. The highest TPC and a strong DPPH scavenging activity were obtained using methanol with $1324.92 \mathrm{mg}$ GAE/100g DW and $68.07 \%$, respectively. Our results were in agreement with those obtained by Do et al. (2020). Differences in efficiency can be explained by the higher affinity of phenolic compounds for polar solvents. In fact, the solubility of phenolic compounds is influenced by the polarity of the solvent (Naczk and Shahidi, 2006). However, other factors such as swelling of the plant material and weakening of the solute-matrix interactions could also be involved (Zuorro et al., 2014). Therefore, methanol was selected for further experiments.

Effect of methanol concentration on total phenolics content and free radical scavenging

The results of the effect of methanol concentration $(25,50,75$, and $100 \%, \mathrm{v} / \mathrm{v})$ on TPC and DPPH scavenging activity were presented in Figures $1 \mathrm{~b}$ and $2 \mathrm{~b}$, respectively. The results showed no significant difference between 50 and $75 \%$ on FRSA. However, the highest TPC (1345.46 mg GAE/100g DW) of $F$. officinalis was obtained with 50\% methanol. On the other hand, the lowest values $(908.34 \mathrm{mg}$ 
GAE/100g DW for TPC and $47.17 \%$ for FRSA) were obtained using $100 \%$ methanol. Our results were in accordance with those obtained by Hashim et al. (2016), who found that 50\% methanol was the best solvent for phenolic compounds extraction from beetroot peel and pulp. According to Garcia-Salas et al. (2010), organic solvent and water mixtures have shown to be more effective in extracting phenolic compounds than mono solvents.

Effect of sample to solvent ratio on total phenolics content and free radical scavenging

Based on previous results concerning the best solvent type and concentration which was 50\% methanol, the effect of sample to solvent ratio on TPC and FRSA was evaluated. The extraction was repeated by varying the sample to the solvent ratio $(0.2,0.4,0.6$, and $0.8 \mathrm{~g} / 10 \mathrm{~mL})$ while fixing the extraction time at 30 minutes. The statistical analysis (one-way ANOVA) showed that the sample to solvent ratio had a significant effect $(p<0.05)$ on TPC and FRSA (Figures 1c and 2c). A high TPC and a strong free radical scavenging were obtained with the ratio of $0.2 \mathrm{~g} / 10 \mathrm{~mL}$ with values of $1339.63 \mathrm{mg}$ GAE/100g DW and $72.54 \%$. These results agreed with those obtained by Chaalal et al. (2012), who found that $0.2 \mathrm{~g} / 10 \mathrm{~mL}$ was the best ratio for phenolic compounds extraction from prickly pear (Opuntia ficus indica) seeds. As shown in Figures $1 \mathrm{c}$ and $2 \mathrm{c}$, the increase of sample to solvent ratio induced the decrease of TPC and FRSA. This can be explained by the mass transfer principle according to Fick's law based on the assumption of a linear relation between solute dispersive mass flux and concentration gradient existing between solvent and solid matrix (Meziant et al., 2018).

\section{Effect of temperature on total phenolics content and free radical scavenging}

In order to study the effect of heating on TPC and DPPH scavenging activity of $F$. officinalis, the extractions were performed with different temperatures ranging from 25 to $70^{\circ} \mathrm{C}$ (Figures $1 \mathrm{~d}$ and 2d). Our results indicated that the best extraction temperature for phenolic compounds was $55^{\circ} \mathrm{C}$ with $1544.22 \mathrm{mg} \mathrm{GAE} / 100 \mathrm{~g}$ DW. The DPPH followed the same pattern as TPC. The extract obtained at this temperature $\left(55^{\circ} \mathrm{C}\right)$ revealed a strong DPPH scavenging activity with a value of $68.81 \%$ and then decreased with using $70^{\circ} \mathrm{C}$. Our results are in agreement with those obtained by Pinelo et al. (2005) and Zhong et al. (2019).

It should be noticed that increasing temperature favors the extraction of phenolic compounds by increasing the solubility of the solute and diffusion coefficient, as suggested by Pinelo et al. (2005). However, at a certain temperature level, the phenolic yield decrease due to the presence of heat-sensitive compounds (Djabali et al., 2020). From obtained results, the increase of temperature from 55 to $70^{\circ} \mathrm{C}$ not affected TPC but reduced significantly antioxidant activity.

\section{Effect of time on total phenolics content and free radical scavenging}

The selection of the best extraction time was the final step of single-factor experiments. The effect of extraction time on the phenolic compounds recovery and DPPH scavenging activity was examined for 30,60, 90, and 120 minutes and the results were shown in Figures 1e and 2e. The recovery of phenolic compounds 
in parallel with antioxidant activity significantly increased with extraction time from 30 to $120 \mathrm{~min}$. This duration allowed extraction of $1886.03 \mathrm{mg}$ GAE/100g DW of TPC and expressing $71.21 \%$ of antioxidant activity. Hence, the best extraction time of phenolic compounds from fumitory was $120 \mathrm{~min}$.
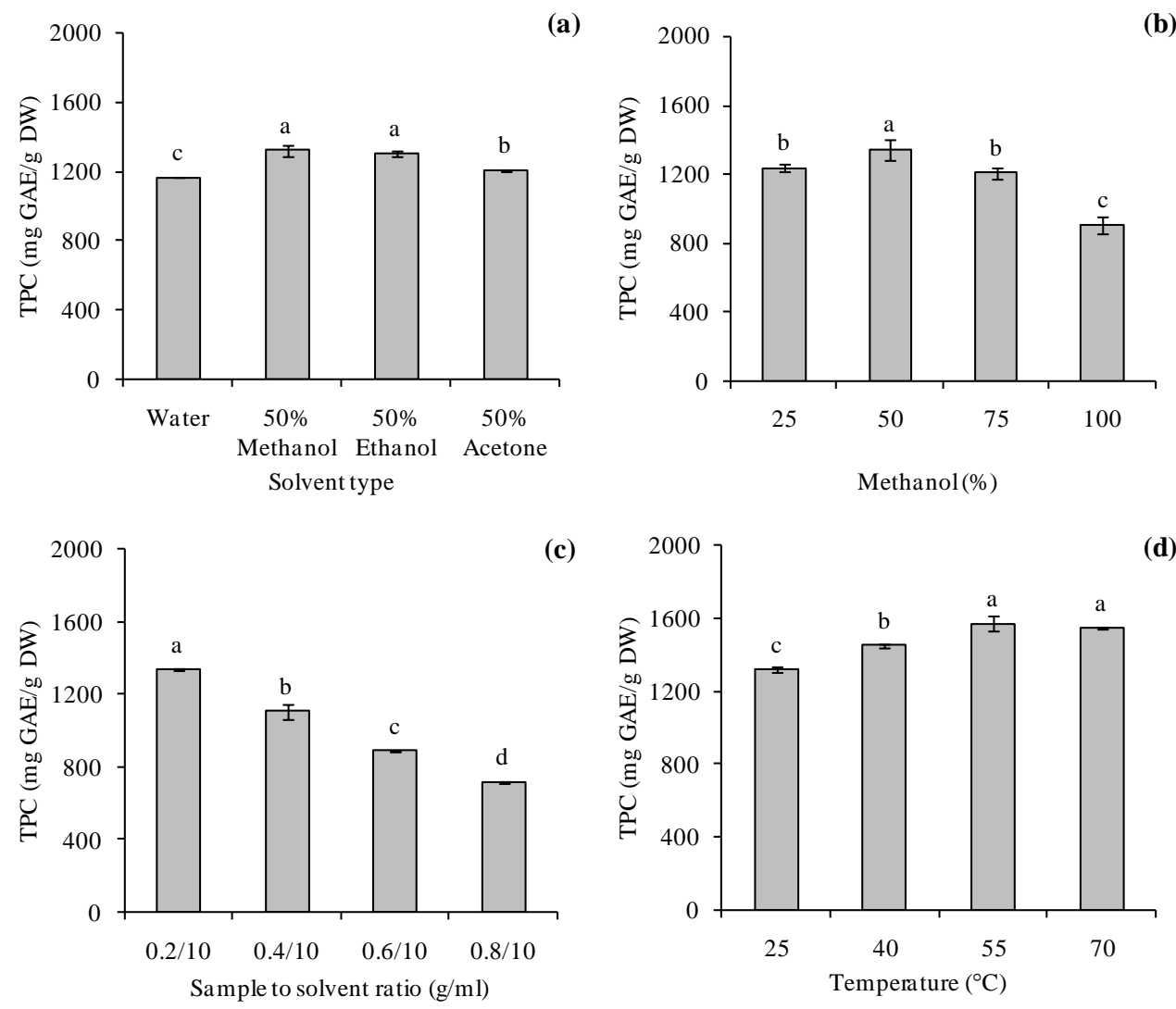

(e)

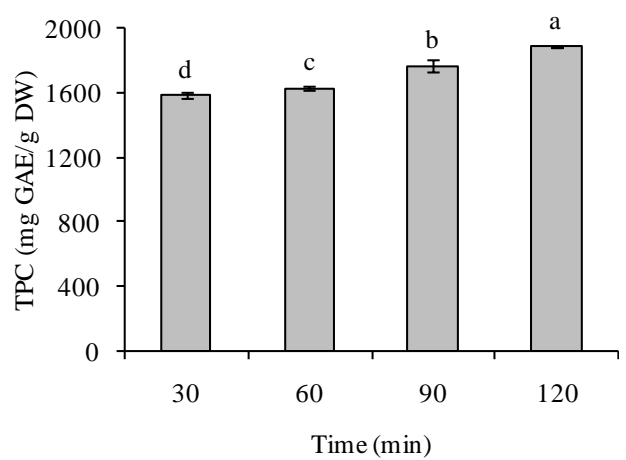

Figure 1. Influences of solvent type (a), solvent concentration (b), sample to solvent ratio (c), temperature (d), and time (e) on total phenolics extraction from F. officinalis. 

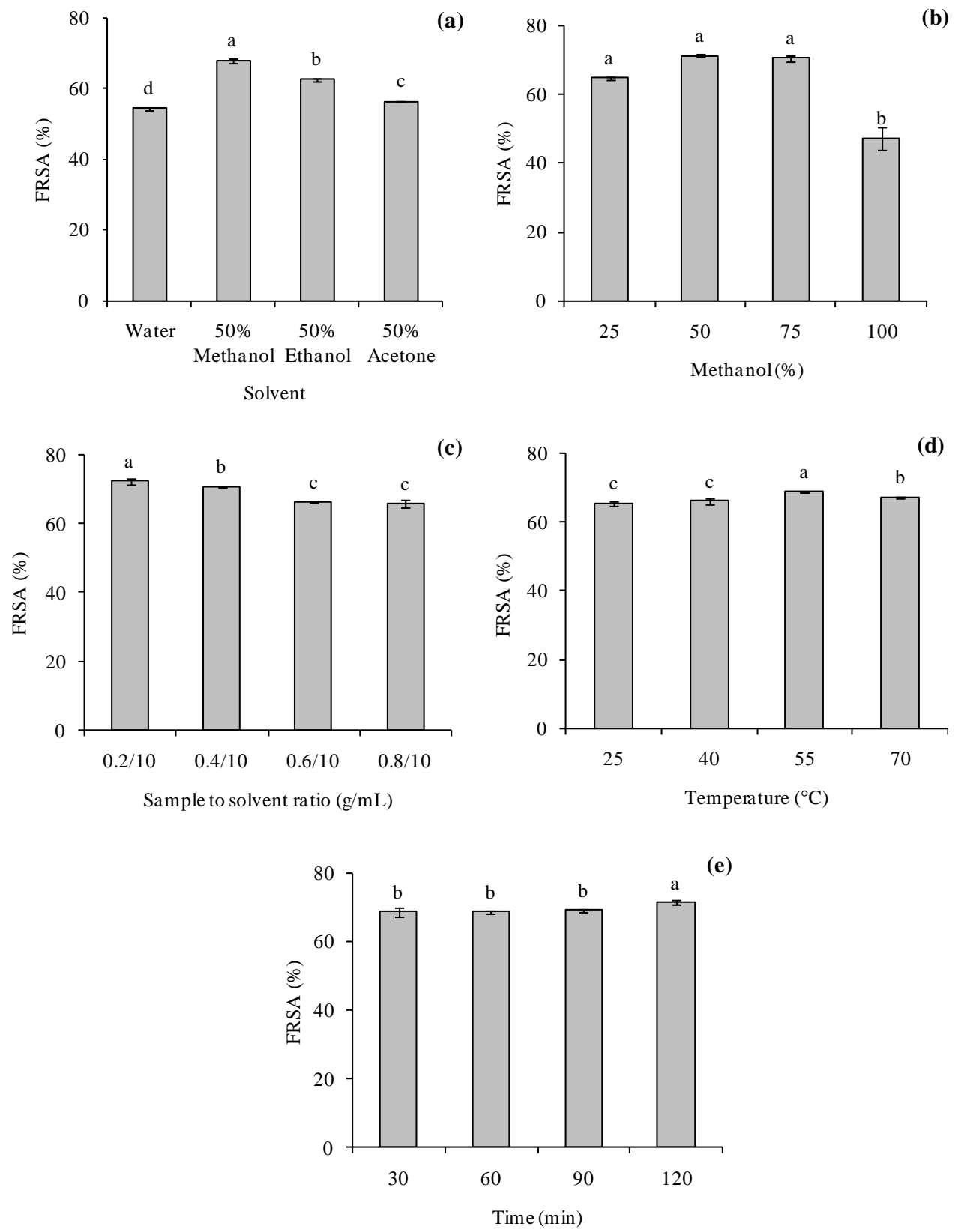

Figure 2. Influences of solvent type (a), solvent concentration (b), sample-to-solvent ratio (c), temperature (d), and time (e) on DPPH free-radical scavenging activity of $F$. officinalis.

The obtained results were in agreement with those reported by Bachir bey et al. (2013) and Che Sulaiman et al. (2017), who found that 120 min was the optimal extraction time of phenolic compounds from dark dried Ficus carica and 
Clinacanthus nutans leaves, respectively. In general, prolonged extraction time would lead to more oxygen exposure, representing a potent factor of phenolic compounds oxidation (Naczk and Shahidi, 2006).

\section{Response surface methodology}

\section{Model fitting and analysis of variance}

Based on the single-factor experimental results, the RSM approach was employed using the Box-Behnken design (BBD) to investigate the effects of solvent concentration, extraction time, and temperature on TPC and FRSA. Fifteen essays, including the three repetitions of central point, in order to check the reproducibility of the extraction process and standard error, were performed. Table 1 presents the design matrices of the actual experiments using BBD and the predicted data for the response variables. Experimental and predicted values for TPC and DPPH scavenging activity were quite similar. The coefficient of determination $\left(\mathrm{R}^{2}\right)$ was 0.91 and 0.93 for TPC and FRSA, respectively; in other words, only $9 \%$ and $7 \%$ respectively of variations are not explained by the model.

Table 1. Experimental design and experimental and predicted values for total phenolic content and free radical scavenging activity of $F$. officinalis.

\begin{tabular}{cccccccc}
\hline & \multicolumn{3}{c}{ Independent variable } & \multicolumn{3}{c}{ TPC (mg GAE/100g } & \multicolumn{2}{c}{ FRSA (\%) } \\
\cline { 2 - 8 } Run & $\begin{array}{c}\text { Solvent } \\
\text { Concentration }\end{array}$ & $\begin{array}{c}\text { Temp. } \\
\left(\mathrm{C}^{\circ}\right)\end{array}$ & $\begin{array}{c}\text { Time } \\
(\mathrm{min})\end{array}$ & Experimental & Predicted & Experimental Predicted \\
1 & 50 & 75 & 50 & 1231.80 & 1237.81 & 70.70 & 74.34 \\
2 & 50 & 35 & 190 & 1381.88 & 1375.87 & 62.98 & 59.34 \\
3 & 50 & 55 & 120 & 1511.56 & 1510.59 & 71.96 & 71.93 \\
4 & 50 & 55 & 120 & 1511.56 & 1510.59 & 71.92 & 71.93 \\
5 & 20 & 55 & 190 & 1524.67 & 1477.86 & 64.02 & 67.43 \\
6 & 50 & 75 & 190 & 1045.3 & 1124.89 & 71.18 & 72.63 \\
7 & 80 & 35 & 120 & 1220.15 & 1252.94 & 38.54 & 43.39 \\
8 & 80 & 75 & 120 & 1297.37 & 1244.55 & 62.46 & 62.23 \\
9 & 50 & 35 & 50 & 1287.17 & 1207.58 & 53.82 & 52.38 \\
10 & 80 & 55 & 190 & 1501.36 & 1474.59 & 68.75 & 67.54 \\
11 & 50 & 55 & 120 & 1508.65 & 1510.59 & 71.92 & 71.93 \\
12 & 20 & 35 & 120 & 1402.28 & 1455.10 & 45.70 & 45.93 \\
13 & 20 & 75 & 120 & 1275.52 & 1242.74 & 67.19 & 62.34 \\
14 & 20 & 55 & 50 & 1520.30 & 1547.07 & 65.02 & 66.23 \\
15 & 80 & 55 & 50 & 1303.20 & 1350.01 & 66.88 & 63.47 \\
\hline
\end{tabular}

TPC, total phenolic content; FRSA, free radical scavenging activity.

According to Jumbri et al. (2015), the more the $\mathrm{R}^{2}$ value is close to 1 , the more empirical model has a strong explanation. Indeed, the adjusted coefficients of 
determination (Adj $R^{2}$ ) values were 0.75 for TPC and 0.79 for FRSA. The adjusted $\mathrm{R}$-square (Adj. $\mathrm{R}^{2}$ ) showed the descriptive power of the regression models while including the significant terms (Che Sulaiman et al., 2017). ANOVA analysis showed that the $p$-values of the two models were less than 0.05 (Table 2). $p$-values were used as a measure to check the significance of each coefficient. When the $p$-value is small, the corresponding coefficient is more significant. Another way to verify and confirm the validity of the model is $F$ values. A large $F$ value is indicative that the independent variables have a significant impact on the respective response variables. Our results showed that $F$ values of 5.71 and 7.00 for TPC and DPPH scavenging activity, respectively, indicated that the models were significant (Tan et al., 2016).

Table 2. Estimation of regression coefficients, Standard error, and Student's t-test results of response surface for total phenolic content and free radical scavenging activity.

\begin{tabular}{lcccc}
\hline \multicolumn{1}{c}{ Parameter } & Estimate & Std. error & t Ratio & Prob. $>|\mathbf{t}|$ \\
\hline $\begin{array}{l}\text { Total phenolic contents } \\
\text { Model }\end{array}$ & & & & \\
$\mathrm{R}^{2}=0.91$ & Adj. $\mathrm{R}^{2}=0.75$ & & & $0.0347^{*}$ \\
Intercept & 1510.591 & 41.866 & 36.08 & $<0.0001^{*}$ \\
$x_{1}$ & -50.086 & 25.638 & -1.95 & 0.1082 \\
$x_{2}$ & -55.186 & 25.638 & -2.15 & 0.0840 \\
$x_{3}$ & 13.842 & 25.638 & 0.54 & 0.6124 \\
$x_{1} \times x_{2}$ & 50.997 & 36.257 & 1.41 & 0.2186 \\
$x_{1} \times x_{3}$ & 48.447 & 36.257 & 1.34 & 0.2391 \\
$x_{2} \times x_{3}$ & -70.303 & 36.257 & -1.94 & 0.1102 \\
$x_{1} \times x_{1}$ & 7.041 & 37.738 & 0.19 & 0.8593 \\
$x_{2} \times x_{2}$ & -218.803 & 37.738 & -5.80 & $0.0022^{*}$ \\
$x_{3} \times x_{3}$ & -55.247 & 37.738 & -1.46 & 0.2031 \\
\hline Free radical scavenging activity & & & \\
Model & & & & $0.0226^{*}$ \\
$\mathrm{R}^{2}=0.93$ & Adj. $\mathrm{R}^{2}=0.79$ & & & \\
Intercept & 71.932 & 2.632 & 27.33 & $<0.0001^{*}$ \\
$x_{1}$ & -0.661 & 1.611 & -0.41 & 0.6984 \\
$x_{2}$ & 8.811 & 1.611 & 5.47 & $0.0028^{*}$ \\
$x_{3}$ & 1.313 & 1.611 & 0.81 & 0.4523 \\
$x_{1} \times x_{2}$ & 0.607 & 2.279 & 0.27 & 0.8005 \\
$x_{1} \times x_{3}$ & 0.716 & 2.279 & 0.31 & 0.7661 \\
$x_{2} \times x_{3}$ & -2.17 & 2.279 & -0.95 & 0.3848 \\
$x_{1} \times x_{1}$ & -8.481 & 2.372 & -3.57 & $0.0160^{*}$ \\
$x_{2} \times x_{2}$ & -9.978 & 2.372 & -4.21 & $0.0084^{*}$ \\
$x_{3} \times x_{3}$ & 2.716 & 2.372 & 1.14 & 0.3041 \\
\hline
\end{tabular}

$x_{1}$, solvent concentration $(\%) ; x_{2}$, temperature $\left({ }^{\circ} \mathrm{C}\right) ; x_{3}$, time $(\min ) . *$ Significant at $p<0.05 ; \mathrm{R}^{2}$, coefficient of determination; Adj. $\mathrm{R}^{2}$, adjusted coefficient of determination.

\section{Effect of regression parameters}

Table 2 presents the effects of independent variables on TPC and DPPH scavenging activity. The statistical analysis showed that TPC was significantly 
affected only by the quadratic term of temperature $\left(x_{2}^{2}, p<0.05\right)$, while the DPPH scavenging activity was significantly influenced by the linear term of temperature $\left(x_{2} ; p<0.05\right)$ and the quadratic terms of both methanol concentration and temperature $\left(x_{1}^{2} ; x_{2}^{2}, p<0.05\right)$. Applying multiple regression analysis on experimental data and considering the significant terms, the fitted models can be presented as quadratic polynomial equations (Equation 5 and 6).

$$
\begin{aligned}
& \mathrm{TPC}=1510.591-218.803 x_{2}^{2} \\
& \text { FRSA }=71.932+8.811 x_{2}-8.481 x_{1}^{2}-9.978 x_{2}^{2}
\end{aligned}
$$

where $x_{1}$ : methanol concentration, $x_{2}$ : extraction temperature.

In order to illustrate the effects of the three studied factors $\left(x_{1}, x_{2}\right.$, and $\left.x_{3}\right)$ on TPC and DPPH scavenging activity, the three-dimensional (3D) response surface plots were generated with varying two factors in the experimental field and keeping the third at the central level. Figure 3a illustrated the combined effect of solvent concentration $\left(x_{1}\right)$ and temperature $\left(x_{2}\right)$ on the TPC and FRSA. Extraction temperature showed a significant quadratic effect on TPC and both linear and quadratic effects on DPPH scavenging activity. Therefore, the TPC progressively increased with increasing temperature until reaching $54.40^{\circ} \mathrm{C}$ and then began to decrease. Increasing temperature promotes extraction by improving both solubility of solutes and the diffusion coefficient. However, elevated temperatures can degrade phenolic compounds (Hismath et al, 2011).

Our results showed that the temperature had a significant negative quadratic effect on the extraction of phenolic compounds; this can be explained by the thermosensitivity of certain compounds in these extracts. Therefore, high temperatures resulted in the degradation of these compounds. This result was similar to that obtained by Bachir bey et al. (2014), who found that extraction temperature exerts positive linear and negative quadratic effects on extracting phenolic compounds from dried fig. This indicates that at relatively low temperatures, the extraction of phenolics was enhanced by heating, but at high temperatures, the degradation of these compounds will occur. Figure $3 \mathrm{~b}$ depicted the effects of solvent concentration $\left(x_{1}\right)$ versus time extraction $\left(x_{3}\right)$. The TPC and DPPH scavenging activity slightly increased with methanol concentration until reaching $1510.10 \mathrm{mg}$ GAE/g DW and $71.85 \%$, respectively. This observation could be explained by the increase of solvent polarity with the addition of water until obtaining an adequate polarity for phenolic solubilization (Iglesias-Carres et al., 2019). Previous studies have reported that organic solvent /water mixtures favor the extraction of phenolic compounds from plants compared to pure solvents (Benkerrou et al., 2018; Saci et al., 2018; Ezzoubi et al., 2021).

Figure $3 \mathrm{c}$ represented the effects of extraction temperature $\left(x_{2}\right)$ and time $\left(x_{3}\right)$ on the two responses at a central level of methanol concentration. The highest phenolic compounds content was obtained at $168.02 \mathrm{~min}$. The extraction time showed no linear or quadratic effect on TPC and DPPH scavenging activity. 

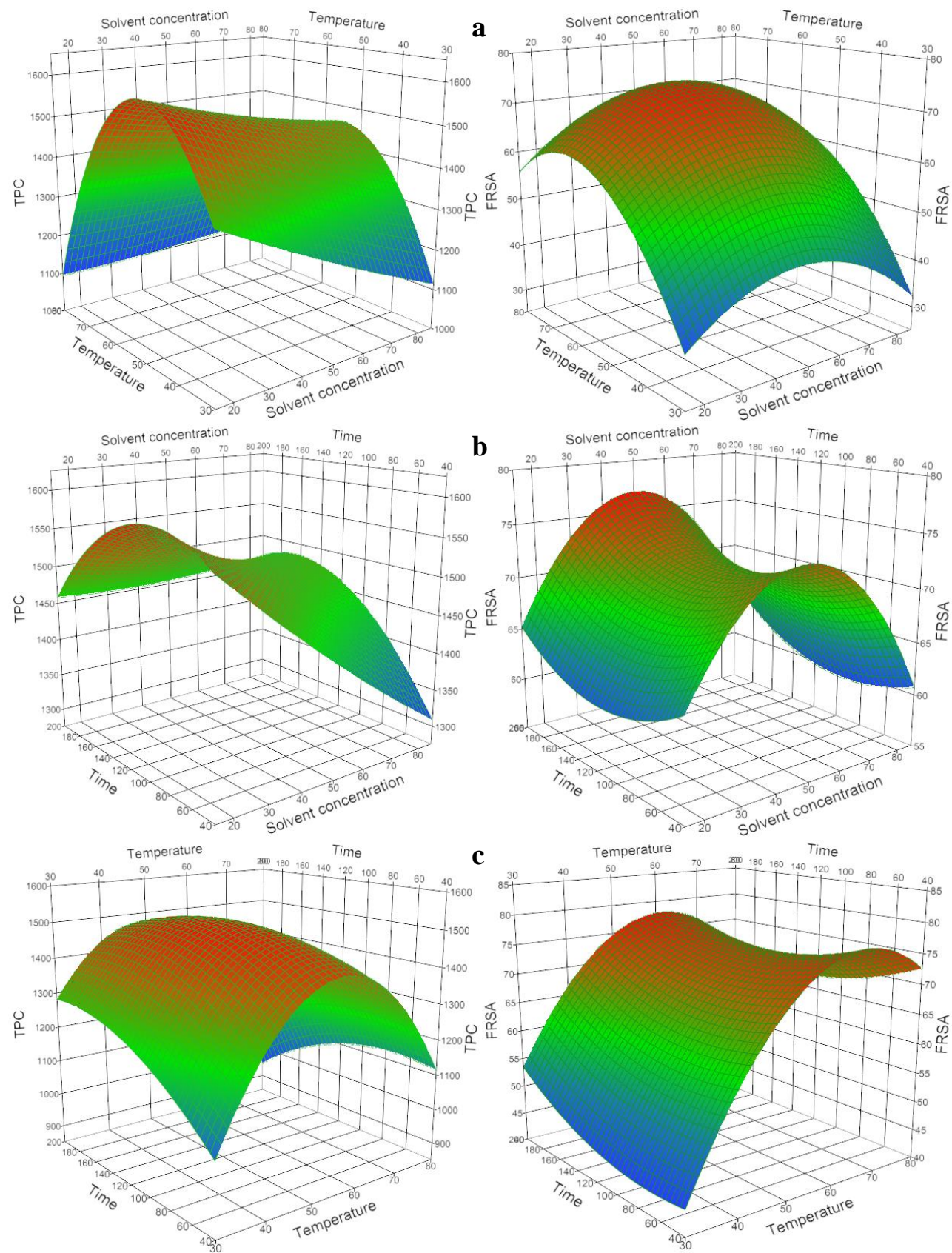

Figure 3. Response surface plots showing the effects of solvent concentration and time (a), solvent concentration and temperature (b), temperature and time (c) on TPC (total phenolic content) and FRSA (free radical scavenging activity) of $F$. officinalis. 


\section{Optimal conditions}

The optimal conditions proposed by the developed models were $47 \%$ methanol, $54.40^{\circ} \mathrm{C}$, and 168.02 min with predicted values for the responses of $1498.97 \mathrm{mg}$ GAE/100g DW (TPC) and $73.81 \%$ (antioxidant activity). An experimental test was carried out by applying the theoretical optimal conditions of the three optimized parameters in order to validate these required conditions and obtain responses. The practical results obtained under the optimal conditions for the responses were $1510.10 \mathrm{mg}$ GAE/100g (TPC) and $71.85 \%$ (FRSA), denoting that these experimental findings were close to the predicted values. Therefore, these results confirmed the validity of the quadratic models and demonstrated that the response surface methodology could be applied effectively to optimize the extraction of phenolic compounds from fumitory (Fumaria officinalis L.).

\section{Bioactive contents and antioxidant activities from the optimal extract}

After the validation of optimal conditions of antioxidants extraction from Fumaria officinalis, the obtained optimal extract was then used to estimate total flavonoid and tannin contents as well as ABTS scavenging and iron-chelating activities (Table 3). TPC for aerial part of $F$. officinalis extract was $1510.10 \pm 2.52 \mathrm{mg}$ GAE/100g DW, higher than obtained by Păltinean et al. (2017) and Safari et al. (2018) and lower than found by Edziri et al. (2020). TFC from the optimal extract of $F$. officinalis was $629.30 \pm 34.84 \mathrm{mg} \mathrm{QE} / 100 \mathrm{~g}$. This result was higher than those of Safari et al. (2018) and lower than Edziri et al. (2020). However, the total tannin content was estimated to be $706.67 \pm 32.15 \mathrm{mg} \mathrm{QE} / 100 \mathrm{~g}$.

Furthermore, F. officinalis methanol extract has been subjected to the antioxidant activities tested by three different methods, DPPH and ABTS scavenging activities and iron-chelating test. $F$. officinalis extract exhibited a good DPPH radical scavenging $(71.85 \%)$ and a moderate ABTS scavenging activity (41.95\%). Our results were lower than those obtained by Jaberian et al. (2013) and Stanojević et al. (2018). However, a strong activity was obtained regarding the iron-chelating assay (87.85\%), and according to our knowledge, this is the first study that evaluated the iron-chelating activity of $F$. officinalis extract.

Table 3. Bioactive contents and antioxidant activities of optimal extract.

\begin{tabular}{llll}
\hline \multicolumn{2}{c}{ Bioactive contents } & \multicolumn{3}{c}{ Antioxidant activities } \\
\hline TPC & $1510.10 \pm 2.52$ & $\mathrm{DPPH}^{\mathrm{o}}$ scavenging activity (\%) & $71.85 \pm 0.92$ \\
TFC & $629.30 \pm 34.84$ & $\mathrm{ABTS}^{\mathrm{o}+}$ scavenging activity (\%) & $41.95 \pm 0.64$ \\
TTC & $706.67 \pm 32.15$ & $\mathrm{Fe}^{2+}$ chelating activity (\%) & $87.85 \pm 2.19$ \\
\hline
\end{tabular}

TPC, total phenolic content (mg GAE/g 100g DW); TFC, total flavonoid content (mg QE/100g DW); TTC, total tannin content (mg CE/100g DW).

\section{Conclusions}

In this study, RSM was developed to maximize the extraction of phenolic antioxidants from $F$. officinalis using the Box-Behnken design. The optimal 
conditions for phenolic compounds extraction were $47 \%$ methanol, using $54.40^{\circ} \mathrm{C}$ for $168.02 \mathrm{~min}$. Under these conditions, the experimental values of TPC and DPPH scavenging activity were $1510.10 \mathrm{mg}$ GAE $/ 100 \mathrm{~g}$ DW and $71.85 \%$, respectively. The values of these responses were in accordance with the predicted values (1498.97 mg GAE /100g DW for TPC and $73.81 \%$ for FRSA). These findings confirmed the validity of the developed model for the extraction of phenolic compounds and the free radical scavenging activity in the experimental conditions used. Furthermore, RSM was able to determine the optimal conditions for the extraction of phenolic compounds and antioxidant activity. In addition, strong ironchelating and interesting ABTS scavenging activities, as well as related bioactive compounds, were obtained from the optimal extract. These extracted compounds were particularly interesting for their role in diverse biological activities. Moreover, identification and characterization methods should be applied to identify the phenolic compounds present in this extract.

\section{Acknowledgments}

We gratefully acknowledge the technical support of the Laboratory of Applied Biochemistry of the Faculty of Natural and Life Sciences (University of Bejaia) as well as the Algerian Ministry of Higher Education and Scientific Research for the financial support, particularly the DGRSDT.

\section{References}

Adham, A.N., Naqishbandi, A.M., Efferth, T., 2021. Cytotoxicity and apoptosis induction by Fumaria officinalis extracts in leukemia and multiple myeloma cell lines. Journal of Ethnopharmacology 266, 113458.

Al-Snafi, A.E., 2020. Constituents and pharmacology of Fumaria officinalis - A Review. IOSR Journal of Pharmacy 10(1), 17-25.

Bachir bey, M., Louaileche, H., Zemouri, S., 2013. Optimization of phenolic compound recovery and antioxidant activity of light and dark dried fig (Ficus carica L.) varieties. Food Science and Biotechnology 22(6), 1613-1619.

Bachir bey, M., Meziant, L., Benchikh, Y., Louaileche, H., 2014. Deployment of response surface methodology to optimize recovery of dark fresh fig (Ficus carica L., var. Azenjar) total phenolic compounds and antioxidant activity. Food Chemistry 162, 277 282.

Benkerrou, F., Louaileche, H., Bachir bey, M., 2018. Optimized ultrasonic-assisted extraction of total phenolics and antioxidant activity of date (Phoenix dactylifera L.) using response surface methodology. The Annals of the University Dunarea de Jos of Galati. Fascicle VI-Food Technology 42(2), 9-22.

Bezerra, M.A., Santelli, R.E., Oliveira, E.P., Villar, L.S., Escaleira, L.A., 2008. Response surface methodology (RSM) as a tool for optimization in analytical chemistry. Talanta 76, 965-977.

Brand-Williams, W., Cuvelier, M.E., Berset, C., 1995. Use of a free radical method to evaluate antioxidant activity. LWT - Food Science and Technology 28, 25-30.

Chaalal, M., Touati, N., Louaileche, H., 2012. Extraction of phenolic compounds and in vitro antioxidant capacity of prickly pear seeds. Acta Botanica Gallica 159, 467-475. 
Che Sulaiman, I.S., Basri, M., Fard Masoumi, H.R., Chee, W.J., Ashari, S.E., Ismail, M., 2017. Effects of temperature, time, and solvent ratio on the extraction of phenolic compounds and the anti-radical activity of Clinacanthus nutans Lindau leaves by response surface methodology. Chemistry Central Journal 11, 54.

Djabali, S., Makhlouf, F.Z., Ertas, A., Barkat, M., 2020. Effect of heat treatment on polyphenolic compounds and antioxidant activity of lentils (Lens culinaris). Acta Scientifica Naturalis 7, 58-71.

Do, T.H., Truong, H.B., Nguyen, H.C., 2020. Optimization of extraction of phenolic compounds from Ocimum basilicum Leaves and evaluation of their antioxidant activity. Pharmaceutical Chemistry Journal 54, 162-169.

Edziri, H., Guerrab, M., Anthonissen, R., Mastouri, M., Verschaeve, L., 2020. Phytochemical screening, antioxidant, anticoagulant and in vitro toxic and genotoxic properties of aerial parts extracts of Fumaria officinalis L. growing in Tunisia. South African Journal of Botany 130, 268-273.

Ezzoubi, Y., Fadil, M., Bousta, D., El Ouali Lalami, A., Lachkar, M., Farah, A., 2021. Ultrasound-assisted extraction of phenolic compounds from Moroccan Lavandula stoechas L.: Optimization using response surface methodology. Journal of Chemistry 2021, $1-11$.

Garcia-Salas, P., Morales-Soto, A., Segura-Carretero, A., Fernández-Gutiérrez, A., 2010. Phenolic-compound-extraction systems for fruit and vegetable samples. Molecules 15, 8813-8826.

Hashim, N., Shaari, A.R., Soh Mamat, A., Ahmad, S., 2016. Effect of differences methanol concentration and extraction time on the antioxidant capacity, phenolics content and bioactive constituents of Orthosiphon stamineus extracts. MATEC Web of Conferences 78, 01004

Hillis, W.E., Swain, T., 1959. The phenolic constituents of Prunus domestica. II. -The analysis of tissues of the Victoria plum tree. Journal of the Science of Food and Agriculture 10, 135-144.

Hismath, I., Wan Aida, W.M., Ho, C.W., 2011. Optimization of extraction conditions for phenolic compounds from neem (Azadirachta indica) leaves. International Food Research Journal 18(3), 931-939.

Hrelia, S., Angeloni, C., 2020. New mechanisms of action of natural antioxidants in health and disease. Antioxidants 9, 344.

Iglesias-Carres, L., Mas-Capdevila, A., Bravo, F.I., Aragonès, G., Muguerza, B., ArolaArnal, A., 2019. Optimization of a polyphenol extraction method for sweet orange pulp (Citrus sinensis L.) to identify phenolic compounds consumed from sweet oranges. PLOS ONE 14, e0211267.

Jaberian, H., Piri, K., Nazari, J., 2013. Phytochemical composition and in vitro antimicrobial and antioxidant activities of some medicinal plants. Food Chemistry 136, $237-244$.

Jorge, A.J., De La Garza, T.H., Alejandro, Z.C., Ruth, B.C., Noé, A.C., 2013. The optimization of phenolic compounds extraction from cactus pear (Opuntia ficus-indica) skin in a reflux system using response surface methodology. Asian Pacific Journal of Tropical Biomedicine 3, 436-442.

Jumbri, K., Al-Haniff Rozy, M.F., Ashari, S.E., Mohamad, R., Basri, M., Fard Masoumi, H.R., 2015. Optimisation and characterisation of lipase-catalysed synthesis of a Kojic monooleate ester in a solvent-free system by response surface methodology. PLoS ONE 10, e0144664. 
Khamtache-Abderrahim, S., Lequart-Pillon, M., Gontier, E., Gaillard, I., Pilard, S., Mathiron, D., Djoudad-Kadji, H., Maiza-Benabdesselam, F., 2016. Isoquinoline alkaloid fractions of Fumaria officinalis: Characterization and evaluation of their antioxidant and antibacterial activities. Industrial Crops and Products 94, 1001-1008.

Naczk, M., Shahidi, F., 2006. Phenolics in cereals, fruits and vegetables: Occurrence, extraction and analysis. Journal of Pharmaceutical and Biomedical Analysis 41, 15231542.

Meziant, L., Boutiche, M., Bachir bey, M., Saci, F., Louaileche, H., 2018. Standardization of monomeric anthocyanins extraction from fig fruit peels (Ficus carica L.) using single factor methodology. Journal of Food Measurement and Characterization 12(4), 2865-2873.

Naithani, V., Nair, S., Kakkar, P., 2006. Decline in antioxidant capacity of Indian herbal teas during storage and its relation to phenolic content. Food Research International 39, 176-181.

Păltinean, R., Paltinean Mocan, A., Vlase, L., Gheldiu, A., Crisan, G., Irina Ielciu, I., Vostinaru, O., Crisan, O., 2017. Evaluation of polyphenolic content, antioxidant and diuretic activities of six fumaria species. Molecules 22, 639.

Pinelo, M., Rubilar, M., Jerez, M., Sineiro, J., Núñez, M.J., 2005. Effect of solvent, temperature, and solvent-to-solid ratio on the total phenolic content and antiradical activity of extracts from different components of grape pomace. Journal of Agricultural and Food Chemistry 53, 2111-2117.

Quettier-Deleu, C., Gressier, B., Vasseur, J., Dine, T., Brunet, C., Luyckx, M., Cazin, M., Cazin, J.-C., Bailleul, F., Trotin, F., 2000. Phenolic compounds and antioxidant activities of buckwheat (Fagopyrum esculentum Moench) hulls and flour. Journal of Ethnopharmacology 72, 35-42.

Raafat, K.M., El-Zahaby, S.A., 2020. Niosomes of active Fumaria officinalis phytochemicals: antidiabetic, antineuropathic, anti-inflammatory, and possible mechanisms of action. Chinese medicine 15, 40.

Re, R., Pellegrini, N., Proteggente, A., Pannala, A., Yang, M., Rice-Evans, C., 1999. Antioxidant activity applying an improved ABTS radical cation decolorization assay. Free Radical Biology and Medicine 26, 1231-1237.

Saci, F., Benchikh, Y., Louaileche, H., Bachir bey, M. 2018. Optimization of ultrasoundassisted extraction of phenolic compounds and antioxidant activity from carob pulp (Ceratonia siliqua L.) by using response surface methodology. The Annals of the University Dunarea de Jos of Galati. Fascicle VI-Food Technology 42(1), 26-39.

Safari, M.R., Azizi, O., Heidary, S.S., Kheiripour, N., Ravan, A.P., 2018. Antiglycation and antioxidant activity of four Iranian medical plant extracts. Journal of Pharmacopuncture 21(2), 82-89.

Stanojević, L., Zvezdanović, J., Danilović B., Cvetković, D., Stanojević, J., Ilić, D., Cakić, M., 2018. The antioxidative and antimicrobial activity of the aqueous earth smoke (Fumaria officinalis L.) extract. Advanced technologies 7(2), 31-40.

Suau, R., Cabezudo, B., Valpuesta, M., Posadas, N., Diaz, A., Torres, G., 2005. Identification and quantification of isoquinoline alkaloids in the genus Sarcocapnos by GC-MS. Phytochemical analysis 16, 322-327.

Tan, S.F., Masoumi, H.R.F., Karjiban, R.A., Stanslas, J., Kirby, B.P., Basri, M., Basri, H.B., 2016. Ultrasonic emulsification of parenteral valproic acid-loaded nanoemulsion with response surface methodology and evaluation of its stability. Ultrasonics Sonochemistry 29, 299-308. 
Teodoro, A.J., 2019. Bioactive compounds of Food: Their role in the prevention and treatment of diseases. Oxidative Medicine and Cellular Longevity 2019, 1-4.

Wang, H., Gao, X.D., Zhou, G.C., Cai, L., Yao, W.B., 2008. In vitro and in vivo antioxidant activity of aqueous extract from Choerospondias axillaris fruit. Food Chemistry 106, 888-895.

Zhong, L., Yuan, Z., Rong, L., Zhang, Y., Xiong, G., Liu, Y., Li, C., 2019. An optimized method for extraction and characterization of phenolic compounds in Dendranthema indicum var. aromaticum flower. Scientific reports $\mathbf{9}, 7745$.

Zuorro A., Maffei G., Lavecchia R., 2014. Effect of solvent type and extraction conditions on the recovery of phenolic compounds from artichoke waste. Chemical Engineering Transactions 39, 463-468. 